Article

\title{
The Perception of Ecosystem Services of Mountain Farming and of a Local Cheese: An Analysis for the Touristic Valorization of an Inner Alpine Area
}

\author{
Rebecca Montrasio ${ }^{1}$, Silvana Mattiello ${ }^{1, *(0)}$, Martina Zucaro ${ }^{2}$, Dino Genovese ${ }^{2}$ \\ and Luca Battaglini ${ }^{2}$ \\ 1 Department of Agricultural and Environmental Sciences-Production, Landscape, Agroenergy, \\ University of Milan, 20133 Milan, Italy; rebecca.montrasio@gmail.com \\ 2 Department of Agricultural, Forestry and Food Sciences, University of Turin, 10095 Grugliasco (TO), Italy; \\ zucaro.martina@gmail.com (M.Z.); dino.genovese@unito.it (D.G.); luca.battaglini@unito.it (L.B.) \\ * Correspondence: silvana.mattiello@unimi.it; Tel.: +39-02-5031-8040
}

Received: 24 June 2020; Accepted: 27 September 2020; Published: 28 September 2020

check for updates

\begin{abstract}
Mountain husbandry systems and their related products may directly or indirectly provide either ecosystem services (ESs) or disservices to humanity. The present study aims to evaluate the perception that a local mountain community has towards animal husbandry in the Lanzo Valleys (Piedmont, Italy) and towards the typical local dairy product, Toma di Lanzo, as well as to investigate the consumers' habits and preferences, to detect possible positive impacts on mountain tourism. A questionnaire was delivered to 233 respondents. The perception of the impact was scored using a five-point Likert scale. The results show a very positive perception of the product Toma di Lanzo because of its origin and type of processing, with different perceptions of the local society depending on age $(p<0.01)$, residence $(p<0.01)$, and education level $(p<0.05)$. The respondents had a very positive awareness of the impact of mountain livestock farming in the Lanzo Valleys. The most important perceived ESs are cultural identity and maintenance of local breeds. Women, non-residents, and respondents with an intermediate education level generally had a more positive perception of ESs. There was a very low perception of disservices derived from mountain animal farming. The main perceived obstacles to the spread of benefits derived from these farming systems were the scarce presence of specific supporting politics and the low income generated by mountain farming activities. The coexistence of touristic activities and extensive livestock farming systems has to be associated with a better promotion of mountain products like Toma di Lanzo to improve the sustainability of mountain regions.
\end{abstract}

Keywords: Italian Alps; ecosystem services; mountain farming; typical dairy products; local communities

\section{Introduction}

The concept of ecosystem services is rooted in the simple notion that humanity is dependent on the natural environment in which it lives [1]. According to the Millennium Ecosystem Assessment [2], Ecosystem Services (ESs) are defined as "the direct and indirect benefits that ecosystems provide to humanity" and are divided into four categories: provisioning (material or energy outputs), regulating (biophysical processes providing benefits such as climate regulation or water purification), supporting (processes that allow the functioning of other ecosystems that, in turn, provide other services, such as nutrient cycles, soil formation, photosynthesis, or pollination), and cultural (recreational, aesthetic, and spiritual benefits).

Mountain agro-ecosystems are defined by [3] as highly multifunctional, since, in addition to providing private goods, they also offer a wide range of public goods. In particular, mountain livestock 
farming systems are peculiar ecosystems based on the direct use of pastures by animals, and they provide several provisioning services to humanity, among which the most recognized is that of supplying food, leather, fiber, and manure [4]. Additionally, they provide many non-provisioning services that are extremely relevant for society, such as genetic conservation, water regulation and purification, pollination, landscape maintenance, recreational activity, ecotourism, the production of cultural heritage, and others [5], whose economic quantification is difficult, as they are difficult to privatize. Furthermore, depending on the intensity of the production system and on the use of resources $[1,6]$, livestock farming systems can also be responsible for the production of disservices, such as damage to the landscape, the hydrology, and the environment [6].

Unfortunately, nowadays, we are assisting in a crisis of mountain livestock systems characterized by a progressive/gradual abandonment of marginal agricultural areas and by a progressive specialization on a few production processes at the expense of the high product diversification that occurred during the historical periods of the highest demographic peaks [7]. During the 20th century, this marginalization process, which occurred mainly in inhabited intermediate mountain slopes, has been progressively increasing, and at the same time, we assisted a rapid development of the large alpine valley bottoms and the adjacent plain areas. This dynamic, also typical for the Northwestern Italian Alps, was particularly favored by the migration of local mountain people towards big factories and urban centers in the plains [8-10], thus creating crisis conditions for the traditional alpine identity and the progressive marginalization of alpine spaces [11]. The number of traditional livestock farms in the middle mountains, mainly oriented to local/typical cheese production, has been significantly decreasing, and many of them had to modify their traditional characteristics in order to maintain economic sustainability [12]. As a consequence of the abandonment and change of these systems, many meadows and pastures turned into forested areas, most of the traditional rural buildings collapsed, and water minute regulation and terracing have been gradually disappearing.

In the context of Alpine regions, this mountain agricultural crisis of pasture-based systems determined the substantial loss of relevant landscape outlines (also particularly relevant for tourism [13]) and of other fundamental ecosystem services [14], including the loss of typical food products, which are also assuming a growing importance for tourists [15-17], and which may thus help in the valuation of mountain livestock systems by increasing their economic sustainability.

For these reasons, the survival of these systems is strategic for safeguarding the cultural heritage they represent, (also from a touristic point of view), which would be possible only if they become part of a local system's programming [18-20]. Unfortunately, the surviving traditional mountain livestock farms are characterized by a low spirit of enterprise, which is mainly family-centered [21]. Their products cannot compete with markets of larger areas, and only the integration of their income with touristic multiservice approaches may allow the farms to have economic sustainability [22,23].

The European Union has also acknowledged the identification and the promotion of local products from mountain farming systems as a priority case through the "mountain product" label as a strategy to sustain local development politics of alpine valleys $[19,24,25]$. The strong geographical connotation derived from labeling may, in fact, generate an added value for mountain products $[17,24,26]$. However, all these processes need to be sustained both by the community and by an innovative process of change that farmers should initiate $[27,28]$.

In order to value ecosystem services, it is important to underline that provisioning services can be marketed as "private goods" at a market price, whereas supporting, regulating, and cultural services are often grouped as "non-provisioning" services and they are "public": All individuals can use them, and their use by one subject does not reduce their availability for others [29]. Therefore, their economic value is often invisible, and most of the time, they are taken for granted. For this reason, it is important to quantify not only their economic value, but also their socio-cultural value, both for local communities [30] and for visitors (e.g., tourists). Socio-cultural values play an important role in determining the quality of natural ecosystems: They are a crucial source of well-being and are indispensable for maintaining a sustainable society. However, they are not easy to measure, but they 
can be estimated on the basis of the evaluation of people's preferences and on their decision-making processes, and this requires a socio-cultural approach typical of social sciences [31].

In the process of economic evaluation of ecosystem services, a preliminary step is the knowledge of their perception and the social value attributed to them by the different social actors [32,33]; this information is essential for the understanding of their repercussions on tourist attendance and on the maintenance of open spaces [34]. The awareness of the value of the agricultural landscape and its scenic beauty comes from the perception of ecosystem services and can be evaluated through them [35].

In the frame of tourism enhancement projects based on local mountain products, it becomes interesting to evaluate what perception exists with respect to a product that bears in its specific denomination a reference to an alpine territory or a valley [36,37]. Consumers expect mountain agriculture to be local and mountain products to be healthier than products from other territories [38]. However, research shows that, unlike consumers who live or frequent mountain contexts, some urban consumers find it difficult to recognize the real characteristics of mountain farming systems in the product $[17,39,40]$. In particular, these studies highlight that urban consumers ignore the ecosystem services connected to the product and to its origin in a pastoral landscape [3,41]. A deeper knowledge of the landscape origin and of the related food products may serve as a collective contribution to the sustainability of the fragile sector of mountain farming, for example, through the direct consumption on site of local products and through on-farm visits, as shown for the typical Fontina cheese in Valle d'Aosta [15]. A typical food product, in fact, is a central element in tourism and can be considered as a useful tool to guarantee a strong identity of a geographic area [24], and cheese in particular can be considered as a tourism resource [42].

In the context described above, the evaluation of the perception of ecosystem services and disservices generated by livestock farming for producing typical cheese in an alpine area, as well as the direct knowledge and perception of that product, would be extremely important in order to allow a better compensation of these activities not only in the light of their productive expressions, but also considering all other services and the roles played by these ecosystems for the territory and the society [14], also in terms of touristic valorization [15]. A previous work centered on local farmers [23], which was carried out in the Lanzo Valleys to understand the role of the typical local cheese, Toma di Lanzo, for the survival and for the sustainability of the traditional small-scale production system, highlighted the importance of a process aimed at product innovation (e.g., integration of agritourist services in mountain pastures and marketing) and system innovation (networks between companies and with different local territorial subjects). However, Reference [23] did not take into account the point of view of the local community, represented by residents and visitors; therefore, in this paper, we aim to integrate this scenario with the missing information, i.e., the role of the local community and its perception of the ecosystem services and disservices of mountain livestock farming systems, as well as of a typical local dairy product, in an alpine territory included in the Italian Strategy for Inner Areas, the Lanzo Valleys [43], in order to highlight possible strategies for the sustainable development of the area. Consumers' habits and preferences towards Toma di Lanzo were also investigated to understand the value of the product for tourism and other economic activities, and eventually to answer to the question: Can the perception by the local community of the ecosystem services of livestock farming systems and their related mountain products be helpful for the potential touristic development of an inner area?

\section{Materials and Methods}

\subsection{Study Area}

The research was carried out in the Lanzo Valleys, a territory formed by three valleys (Val Grande di Lanzo, Val d'Ala, and Val di Viù) converging towards the Lanzo Torinese township, located at $30 \mathrm{~km}$ from Turin in the Piedmont region (Western Italian alps) (Figure 1). 


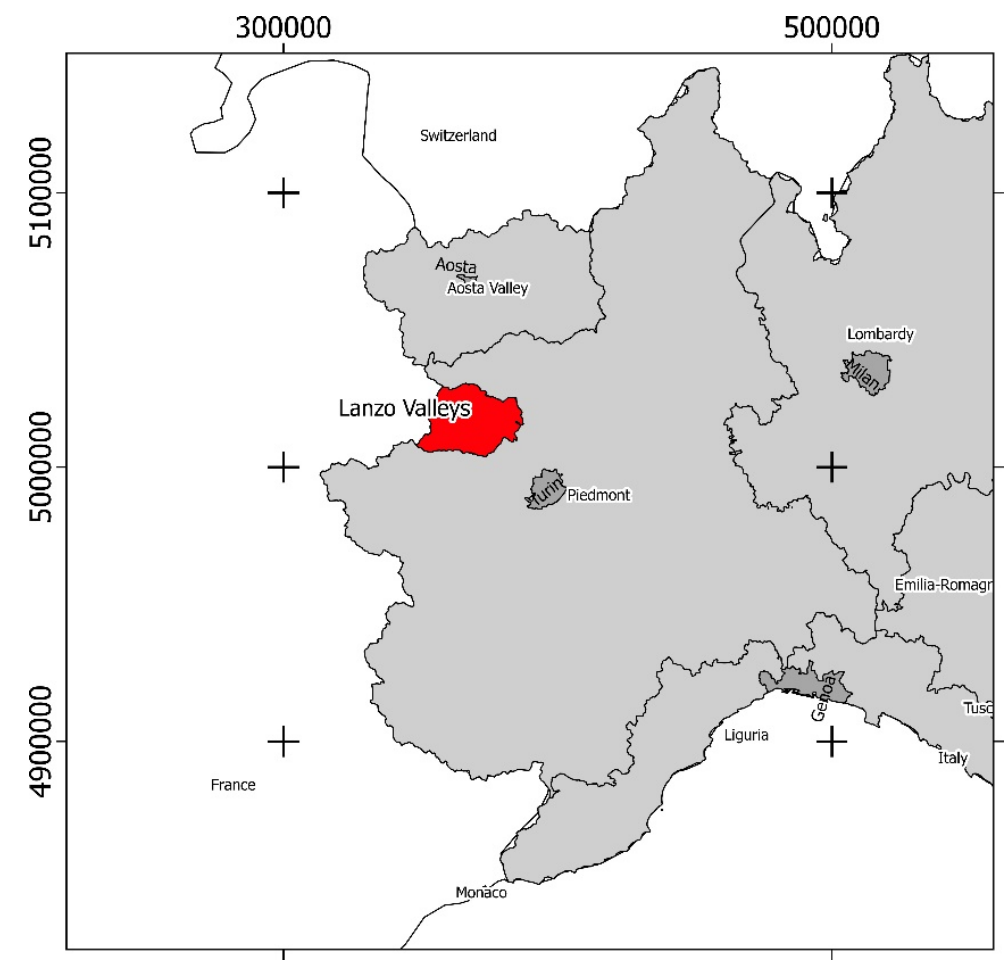

Figure 1. Location of the Lanzo Valleys (in red) in Northern Italy (reference frame: WGS84/UTM32N).

The territory has a surface area of $785 \mathrm{~km}^{2}$ and an altitudinal range between 450 and $3676 \mathrm{~m}$ above sea level (a.s.l.) [44]. The last census (2017) reports a resident population of 24,094 people, slowly decreasing at a yearly rate of $2 \%$ [43]. This trend is linked to the fact that 9 out of 19 municipalities in the Lanzo Valleys have been classified as "peripheral", presenting problems that affect the local quality of life (e.g., scarce infrastructures and accessibility problems typical of marginal mountain areas, with long travel times to reach the main basic services). Since the 19th century, the Lanzo Valleys have been involved in an important touristic development [45], above all with summer residences. However, this development has not been successful in preventing a demographic depopulation during the last century that affected the whole Piedmont mountain territory. Reference [7] evidenced a progressively increasing loss of elements of the anthropogenic landscape and the gradual afforestation of meadows, pastures, and terraced fields between 1978 and 2015. For these reasons, the geographic area of the Lanzo Valleys has been included in the Italian Strategy for Inner Areas [43].

According to the National Database of the Zootechnical Registry [46], in the Lanzo Valleys, there are 199 cattle farms, with 3504 heads, plus a few dairy goat and sheep farms. The most common cattle breeds are Simmental, Pustertaler Sprinzen (Barà), Valdostana Pezzata Rossa, Valdostana Castana, Piemontese, Tarentaise, a few Valdostana Pezzata Nera, and many crossbreeds. The typical dairy product of this area is the Toma di Lanzo, which is a medium-seasoned, semi-hard cheese made of whole or partially skimmed raw cattle milk. The "Association of Toma di Lanzo Producers" was established in May 2013 and drew up a specification for the production of Toma. In addition, the association has implemented a traceability system for the Toma di Lanzo produced in the upper Lanzo Valleys and in alpine pastures in accordance with UNI EN ISO 22005: 2008. Finally, in 2016, Toma di Lanzo became one of the Traditional Agri-Food Products.

\subsection{Data Collection}

Data were collected through a survey carried out by means of a questionnaire adapted from other questionnaires used in similar studies [13,47-50]. The questionnaire consisted of 53 questions, divided into three sections: (1) socio-cultural characteristics of the respondents; (2) consumers' 
habits and preferences of the product Toma di Lanzo, and perception of the impact of the product on the territory; (3) perception of services and disservices provided by mountain farming in the Lanzo Valleys. In this last section, we proposed a list of ecosystem services-Provisioning, Regulating, Supporting, or Cultural—and disservices, which are listed in detail in Table 1.

Table 1. List and description of services (Provisioning, Regulating, Supporting, or Cultural) and disservices proposed in the interview.

\begin{tabular}{|c|c|}
\hline Service & Description \\
\hline Control of invasive species ${ }^{b}$ & Control of invasive species of flora and fauna (e.g., weed control) \\
\hline Control of soil erosion ${ }^{b}$ & $\begin{array}{l}\text { Prevention of land degradation and soil erosion (the roots of trees } \\
\text { and grass ensure stability and soil retention, decreasing the risk of } \\
\text { erosive phenomena) }\end{array}$ \\
\hline Cultural identity ${ }^{\mathrm{d}}$ & Cultural identity and sense of belonging to the valleys \\
\hline Environmental education $^{\mathrm{d}}$ & $\begin{array}{c}\begin{array}{c}\text { Education of general public in a correct behavior and respect for the } \\
\text { environment }\end{array}\end{array}$ \\
\hline Fire control ${ }^{b}$ & Fire prevention by means of control of bush encroachment \\
\hline Food production ${ }^{\mathrm{a}}$ & Production of meat, milk, cheese, etc. \\
\hline Habitat maintenance ${ }^{c}$ & $\begin{array}{c}\text { Habitat maintenance for other animal species (e.g., creation of } \\
\text { shelters or nesting areas for wild fauna) }\end{array}$ \\
\hline Improvement of water quality ${ }^{b}$ & $\begin{array}{l}\text { Improvement of water quality by its purification and regulation of } \\
\text { its infiltration in the soil }\end{array}$ \\
\hline Inspiration for arts and culture ${ }^{d}$ & $\begin{array}{c}\text { Inspiration for arts (e.g., painting, photographs, music, etc.) and } \\
\text { culture (literature, poetry, etc.) }\end{array}$ \\
\hline Maintenance of biodiversity ${ }^{a}$ & $\begin{array}{l}\text { Maintenance of biodiversity, e.g., in terms of number of plant species } \\
\text { present on pasture }\end{array}$ \\
\hline Maintenance of landscape ${ }^{d}$ & $\begin{array}{c}\text { Preservation of a typical landscape (e.g., maintenance of pastures, } \\
\text { paths, and villages used by farmers) }\end{array}$ \\
\hline Maintenance of local breeds ${ }^{c}$ & Genetic conservation of local/autochthonous breeds \\
\hline Pollination ${ }^{b}$ & $\begin{array}{l}\text { Dispersion of seeds and pollen into the environment, favoring the } \\
\text { growth of new plants }\end{array}$ \\
\hline Production of fertilizers ${ }^{a}$ & $\begin{array}{l}\text { Production of natural fertilizers (e.g., manure) as an alternative to } \\
\text { chemical fertilizers }\end{array}$ \\
\hline Production of wool and leather ${ }^{a}$ & Production of wool, other fibers, or leather \\
\hline Recreational opportunities ${ }^{d}$ & $\begin{array}{l}\text { Recreational opportunities for tourists (e.g., farmhouses, sports } \\
\text { involving animals, pet therapy, etc.) }\end{array}$ \\
\hline Religious experiences $^{d}$ & $\begin{array}{l}\text { Religious experiences (religious festivals and pilgrimages, blessings, } \\
\text { patron saints, presence of places of worship) }\end{array}$ \\
\hline Soil fertilization ${ }^{\mathrm{b}}$ & $\begin{array}{l}\text { Direct soil fertilization (i.e., animals supply nutrients to the } \\
\text { surrounding vegetation) }\end{array}$ \\
\hline \multicolumn{2}{|l|}{ Disservice } \\
\hline Greenhouse gas emissions & $\begin{array}{l}\text { Increased emission of greenhouse gases (e.g., methane, nitrous } \\
\text { oxide) }\end{array}$ \\
\hline Loss of biodiversity & Reduction of the variety of plant species \\
\hline Loss of landscape & Reduction of the variety of landscapes \\
\hline Lower air quality & Air contamination (e.g., bad smells) \\
\hline Lower animal welfare & $\begin{array}{l}\text { Lower levels of animal welfare, e.g., due to mistreatment, dirtiness, } \\
\text { poor hygienic conditions }\end{array}$ \\
\hline Lower environmental cleanness & $\begin{array}{c}\text { Dirtiness of the roads, meadows, or other parts of the territory } \\
\text { because of defecation by animals }\end{array}$ \\
\hline Lower food quality & Production of poor-quality food \\
\hline Soil erosion & Soil erosion, e.g., due to the excessive trampling by animals \\
\hline Water pollution and consumption & Pollution and excessive consumption of water \\
\hline
\end{tabular}


The English translation of the questionnaire can be retrieved from https://docs.google.com/forms/d/ e/1FAIpQLScMhgHpJhhokxgiflTeRbezLFUqC8sUGkxZhmhlpheDbFTmdw/viewform?usp=sf_link.

The survey was carried out using a digital questionnaire created with Google Forms, available at the above cited link. Additionally, a few direct interviews were carried out during specific local meetings focusing on Toma di Lanzo. Data collection lasted for about one and a half months (from 27/10/2019 to 10/12/2019) and allowed the collection of 233 questionnaires, 91\% of which were compiled online, and only $9 \%$ were collected from direct interviews. Only persons who knew the Lanzo Valleys (either because they resided there, or because they frequented the area as tourists) were included in the sample.

This questionnaire was disseminated through word of mouth and sharing on channels such as WhatsApp and e-mail, as well as by sharing the link within social networks such as Facebook, selecting target groups related to the territory of the Lanzo Valleys and to the Toma di Lanzo product (e.g., Facebook pages such as Associazione Produttori Toma di Lanzo, Unione montana Valli di Lanzo, Ceronda e Casternone, Uncem Piemonte, or Facebook groups such as Valli di Lanzo... storia foto tradizioni leggende e costume, Eventi Valli di Lanzo). In total, 12 groups and 5 Facebook pages were identified. The compilation of the digital questionnaire was also promoted with the help of the Toma di Lanzo Producers Association and thanks to an article in a local journal [51].

\subsection{Data Analysis}

The perception of the impact was scored by using a five-point Likert scale $(1=$ very negative; $2=$ negative; 3 = neutral; 4 = positive; 5 = very positive for ESs; $1=$ null; $2=$ scarce; 3 = medium; $4=$ high; $5=$ very high for disservices). Scores are expressed as means \pm standard errors (s.e.). A multivariate principal component analysis (PCA) and a hierarchical cluster analysis were initially carried out on impact scores for preliminary data exploration. The scores were also compared using univariate analysis by a Mann-Whitney test depending on sex (males vs. females), age class (18-30 y vs. $31-60$ y vs. $>60$ y), school level (low (primary school) vs. intermediate (high school) vs. high (university or postgraduate degree)), residence (residents vs. non-residents), and cultural background (agricultural vs. non-agricultural). All the analyses were carried out using SPSS version 25.

\section{Results}

\subsection{Characteristics of the Respondents}

The 233 respondents were rather balanced with respect sex: $58.4 \%$ were females and $41.6 \%$ were male; most of them (61.6\%) were aged between 31 and 60 years, $22 \%$ were over 60 years old, and $16.4 \%$ were between 18 and 30 years old. As to education level, only $13.4 \%$ had a basic education (primary school $=1.3 \%$ and lower secondary school $=12.1 \%$ ), whereas $51.7 \%$ of the respondents had an intermediate education level (high school diploma), and 34.9\% had a university or postgraduate degree. More than half of the respondents (57.9\%) were residents in the Lanzo Valleys, while $42.1 \%$ were not, being represented mainly by tourists and by people who knew the territory because they resided in the neighboring areas. Finally, it is interesting that only $19.4 \%$ of the respondents were farmers, while $80.6 \%$ of subjects were unrelated to the agricultural sector.

\subsection{The Toma di Lanzo Product}

Most of the respondents (94\%) had consumed Toma di Lanzo for more than two years, $1.7 \%$ for less than two years, and $4.3 \%$ had never tasted it. Among the consumers (224 subjects), 55.9\% normally buy the product directly from the producer, $36 \%$ in a store, $4.5 \%$ from friends and relatives, $1.80 \%$ at the market, and $1.35 \%$ from various sources; $0.45 \%$ declared that they produce Toma di Lanzo. For $45.49 \%$ of the respondents who consumed Toma di Lanzo, the most important driver to buy the product was the place of origin, while $23.6 \%$ believed that it is essential to consider the type of production, $17.2 \%$ purchase the product when it presents the Toma di Lanzo certification of the 
Producers Association, 9\% thought that the health characteristics of the product are fundamental, and $1.7 \%$ considered the price a crucial factor.

Most of the respondents $(74.29 \%)$ believed that Toma di Lanzo is better than similar products, such as other Toma cheeses produced in Piedmont, while only $0.95 \%$ thought it is worse. For $15.71 \%$ of the sample, there were few differences among various Toma cheeses; $6.19 \%$ believed that there are differences, but not necessarily that they were better or worse, and $1.90 \%$ could not answer the question about the difference between Toma di Lanzo and similar products.

To the question "Would you be willing to pay more for the Toma di Lanzo product with the certification of the Association of Toma di Lanzo producers?", only $19 \%$ of the respondents answered "no". Most of the respondents (68.1\%) answered that they were willing to pay more for the certified Toma di Lanzo, while $12.9 \%$ of them did not know about the "Toma di Lanzo" certification. Of the subjects willing to pay more for the certified Toma di Lanzo, $42.86 \%$ were willing to pay $20 \%$ to $29 \%$ more than the price of a similar product; $26.09 \%$ were willing to pay $10 \%$ to $19 \%$ more, $22.98 \%$ from $30 \%$ to $49 \%$ more, and $6.21 \%$ would pay even $50 \%$ more than for a non-certified "Toma" type cheese.

Almost all the respondents (94.4\%) believed that Toma di Lanzo is closely linked to the territory and culture of the Lanzo Valleys, and $92 \%$ of them thought that its production outside this area would lose value. Most of the respondents (95.7\%) agreed that food products derived from mountain farming contribute to improving the economy in the Lanzo Valleys. A total of $99.1 \%$ of the subjects believed that products obtained from mountain farming have an extra value compared to products produced elsewhere. However, $66.8 \%$ of them believed that this extra value was not adequately communicated to the consumer at the time of sale, and suggested several approaches in order to value the Toma di Lanzo product. For example, they believed that it is important that producers/sellers inform consumers by exposing the history of the product, starting from animal breeding up to the description of the cheese-making process. They also suggest that at the time of the sale, it would be interesting "to exhibit photos of mountain pastures and photos of the cheese processing phases (before, during, and after)." Further suggestions included the organization of guided visits to the mountain pastures where the animals are farmed and the Toma is produced, and the promotion of the product through social media, marketing actions, and ad hoc exhibitions dedicated to Toma di Lanzo. Product labeling, traceability, use of brands such as "Protected Designation of Origin" (PDO) or "Mountain Product", and the inclusion of more information and images representative of the product and type of production in the product label were also suggested. Finally, several subjects highlighted a lack of interest and participation by public bodies in the promotion and enhancement of the territory and its typical products.

As to the local impact of the product, the interviewees believed that Toma di Lanzo has a positive impact on the territory and ecosystems (score $4.17 \pm 0.06$ ), human welfare $(4.17 \pm 0.06)$, and society of the Lanzo Valleys $(4.33 \pm 0.05)$, and a rather positive/neutral impact on the environment $(3.59 \pm 0.063)$. Significant differences were recorded between sexes for the perception of the impact on the territory and ecosystems (males: $4.32 \pm 0.08$, females: $4.06 \pm 0.08 ; p=0.034$ ), as well as among age classes (18-30 y: $4.53 \pm 0.11,31-60$ y: $4.38 \pm 0.06,>60$ y: $4.00 \pm 0.13 ; p=0.005$ ), education levels (low: $4.00 \pm 0.22$, intermediate: $4.29 \pm 0.07$, high: $4.51 \pm 0.08 ; p<0.035$ ), and residence (non-residents: $4.53 \pm 0.06$, residents: $4.18 \pm 0.08 ; p=0.002$ ) for the perception of the impact on the society of the Lanzo Valleys.

\subsection{Perception of Ecosystem Services and Disservices}

In general, all the ecosystem services-either Provisioning, Regulating, Supporting, or Culturalproposed in the interview obtained a good or very good score. The service that obtained the highest average score was the "maintenance of landscape". On the contrary, the aspect that obtained the lowest average score was the production of wool and leather, with an average value that shows a perception of only a fairly positive impact of animal husbandry on the production of leather and wool within the territory of the Lanzo Valleys (Figure 2). 


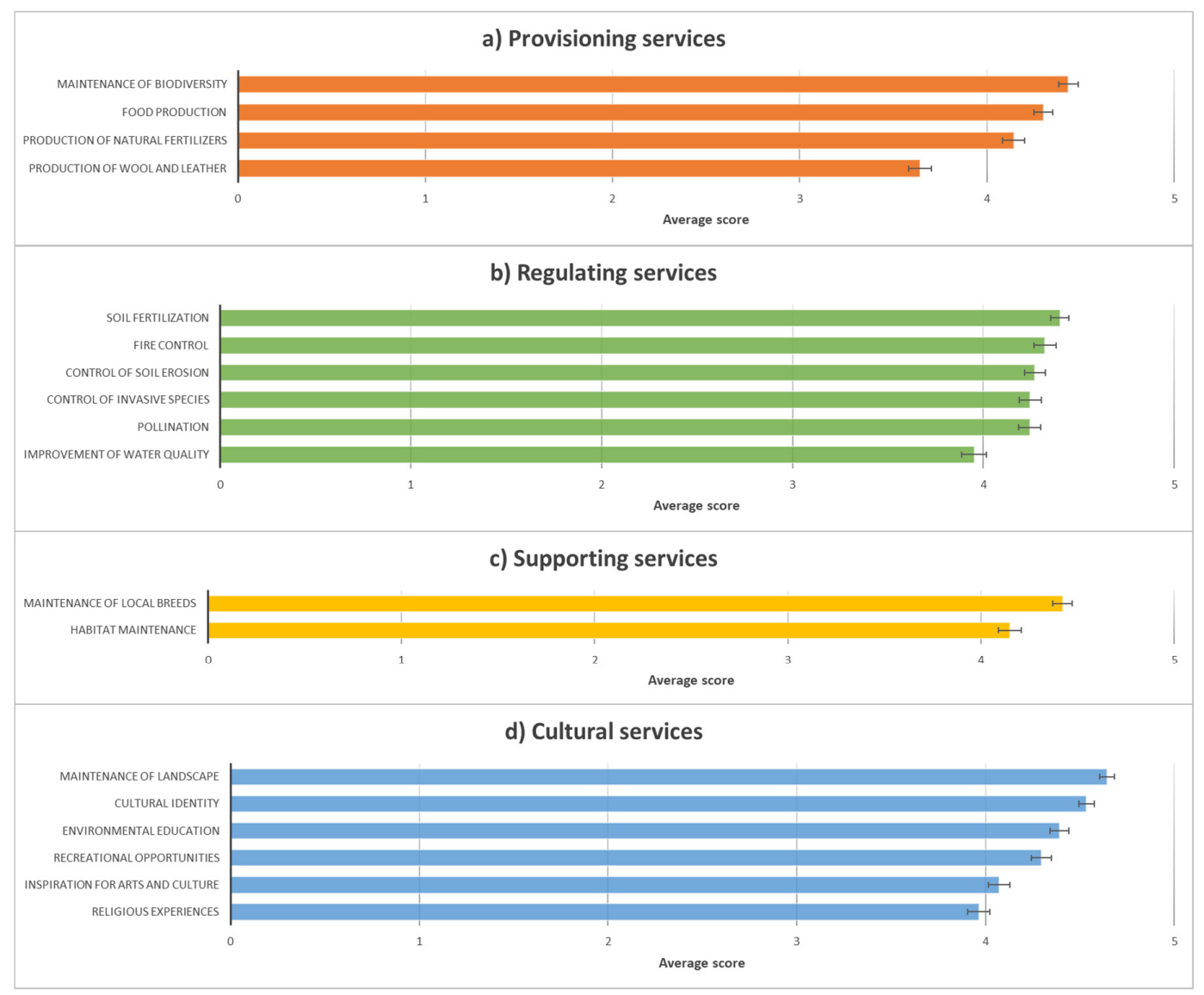

Figure 2. Average scores ( \pm s.e.) of the perception of ecosystem services provided by mountain farming, expressed on a five-point Likert scale (from $1=$ very negative to $5=$ very positive). Services are classed according to the Millennium Ecosystem Assessment (MA, 2005) as follows: (a) Provisioning services; (b) Regulating services; (c) Supporting services; (d) Cultural services.

Multivariate analysis (PCA and cluster analysis) could not highlight clear trends in data distribution depending on sex, age class, education level, residence, or cultural background. However, univariate analysis showed some significant differences that will be presented and discussed.

Females had a higher perception of ESs than males, with significant differences of the effect on maintenance of local breeds $(p=0.01)$, improvement of water quality $(p<0.05)$, pollination $(p<0.01)$, and cultural identity $(p<0.05)$ (Figure 3$)$.

The perception of ESs was statistically lower for respondents with a low education level than for the other two categories, with the highest scores assigned by subjects with a medium education level, and significant differences recorded for pollination (low: $3.94 \pm 0.21$; intermediate: $4.39 \pm 0.07$; high: $4.14 \pm 0.09 ; p<0.05$ ) and habitat maintenance (low: $4.00 \pm 0.22$; intermediate: $4.29 \pm 0.07$; high: $4.00 \pm 0.09 ; p<0.05)$. 


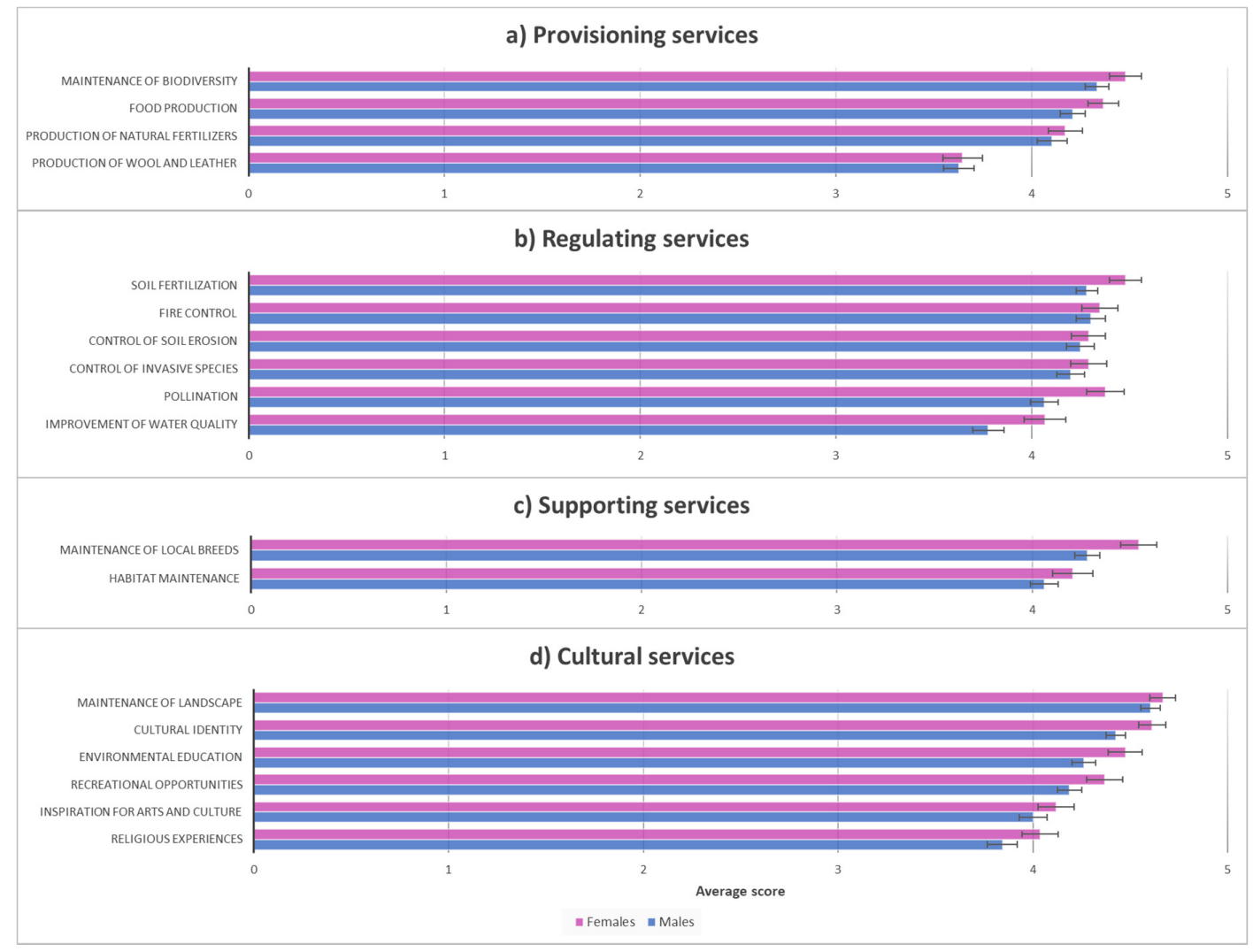

Figure 3. Average scores ( \pm s.e.) of the perception of ecosystem services (classed as: (a) Provisioning services; (b) Regulating services; (c) Supporting services; (d) Cultural services) provided by mountain farming, expressed on a five-point Likert scale (from $1=$ very negative to $5=$ very positive) by the two sexes.

Non-residents showed a more positive perception of 13 out of 18 ESs, with significant differences for fire control $(p<0.05)$ (Figure 4). Finally, no differences in the perceptions of ESs were observed depending on age class or on the cultural background.

The aspects of the territory most appreciated by the respondents were the landscape (for $36.91 \%$ of the respondents) and its tranquility $(32.19 \%)$, followed by the healthy air $(13.30 \%)$, the possibility to engage in sports and outdoor activities $(6.01 \%)$, and the availability of the healthiest food products $(4.72 \%)$. A total of $3.00 \%$ of the respondents declared they agreed with all the points listed, and the remaining part (3.86\%) preferred to express their personal opinions. For example, an interviewee claimed to appreciate the "clean air, genuine food, tranquility, and being able to raise children with the aforementioned living conditions"; another admired the fact that everyone knows each other and that children can play by themselves in the open air.

The impact on all the listed disservices was perceived as low or very low by the respondents (Figure 5). 


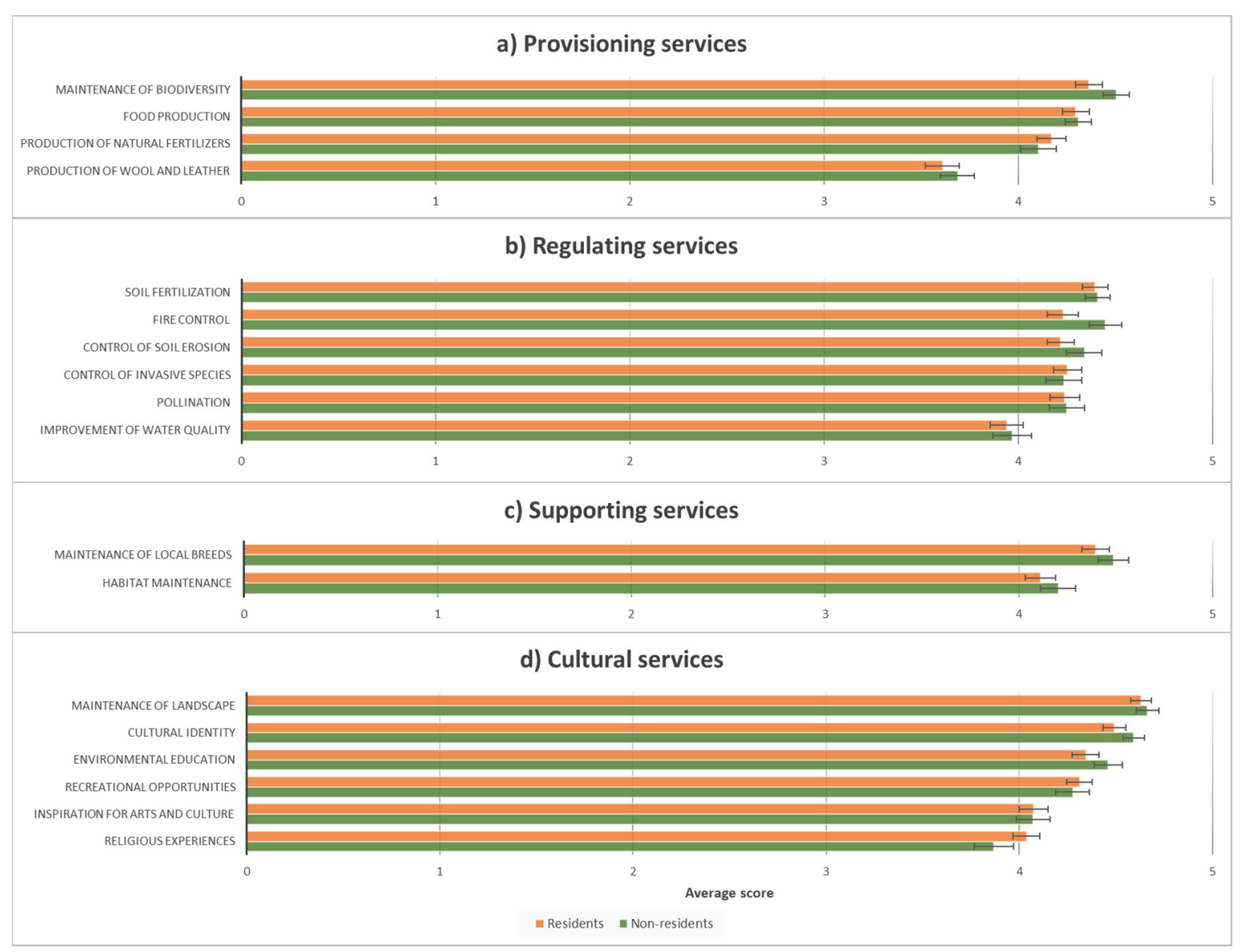

Figure 4. Average scores ( \pm s.e.) of the perception of ecosystem services (classed as: (a) Provisioning services; (b) Regulating services; (c) Supporting services; (d) Cultural services) provided by mountain farming, expressed on a five-point Likert scale (from $1=$ very negative to $5=$ very positive) by residents and non-residents.

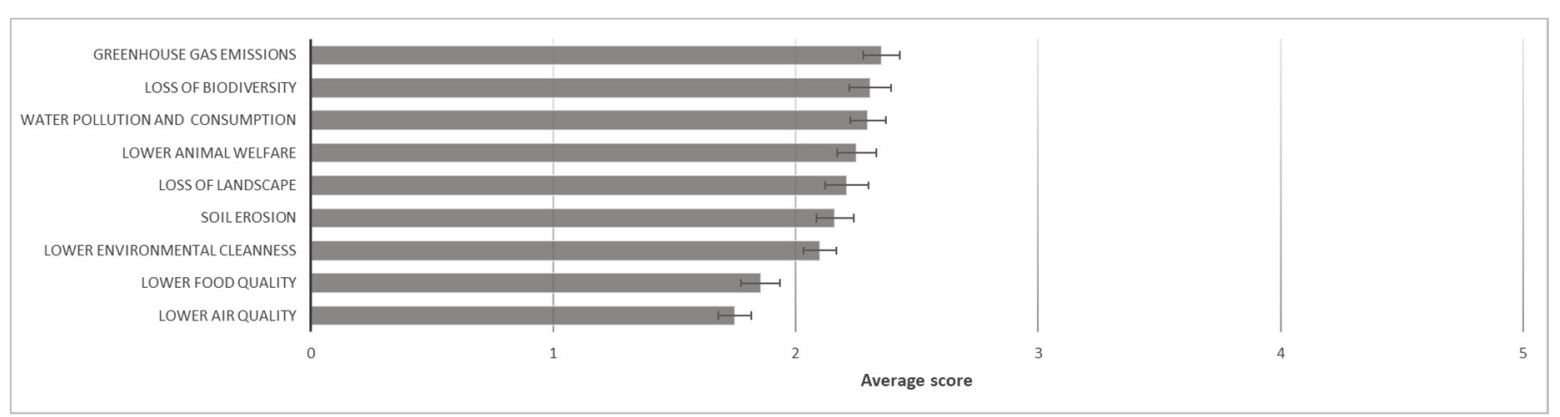

Figure 5. Average scores ( \pm s.e.) of the perception of ecosystem disservices provided by mountain farming, expressed on a five-point Likert scale (from $1=$ null to $5=$ very high).

\subsection{Possible Future Constraints}

Finally, the sample was invited to select which constraints could hinder the supply of ecosystem services provided by mountain livestock farming in the Lanzo Valleys in the future. The respondents could select the different aspects in a multiple-answer question, which is why the total number of answers exceeds the size of the sample. The most perceived constraints were "absence of policies/regulations to support livestock farming in mountain areas" and "insufficient income generated by mountain livestock farming", which were both selected by 138 respondents. The least voted was: "I don't think mountain livestock farming offers ecosystem services in this area", which was selected 
by only seven respondents (Figure 6). Some of the interviewees preferred to give their own opinions. For example, some respondents commented that there is a "lack of willingness by local communities to improve breeding conditions and interaction with tourism" and that it would be necessary "to find common sense administrators to defend the fragile mountain ecosystem", as well as that there is a "poor awareness of the value of one's work and a poor future vision."

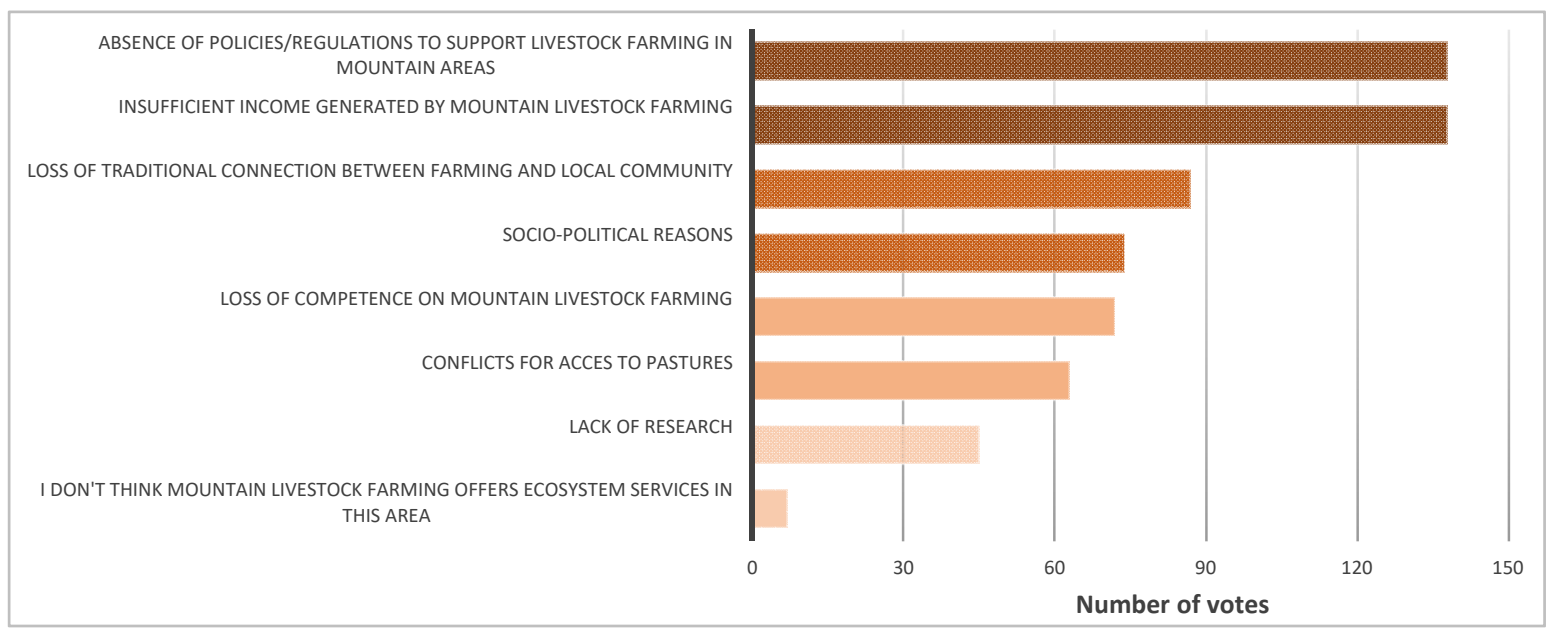

Figure 6. Number of votes assigned by the respondents to the major constraints that could hinder the supply of ecosystem services provided by mountain livestock farming in the Lanzo Valleys. Each respondent could select more than one option.

\section{Discussion}

Considering the small surface area and the low number of people who reside in the Lanzo Valleys, the survey involved quite a high number of respondents, which can be considered representative of the context of the Lanzo Valleys. The use of an online survey certainly played an important role for spreading the questionnaire and allowed the collection of a lot of data in a short time. In fact, most of the questionnaires were filled in on the web. However, this is the possible reason for why the class of subjects over 60 years of age was scarcely represented in our sample, as the survey was mainly disseminated through social networks that are possibly unknown to or not used by elder people.

The Toma di Lanzo cheese is well known in the area, and it is often consumed by most of the respondents, who consider it as an excellent product and believe that a food product obtained from mountain farming represents a source of cultural and economic wealth for the area. This also opens up excellent perspectives for valuing the cheese for so-called cheese tourism, of which several successful examples in many European (e.g., Germany France, Italy, Croatia, Slovenia, Poland) and non-European countries (e.g., New Zealand, Costa Rica, Ecuador, Mexico, Peru) have recently been reviewed by [42].

Despite the generally positive view of Toma di Lanzo, some of the respondents found some critical issues in relation to the product's price and marketing. In addition, respondents noticed a deficiency in terms of information on the cheese's quality and production process. Genovese et al. [23] agree with this perception and confirm that Toma di Lanzo is known only by the resident community, but it is not well known outside of the territory of the Lanzo Valleys. The implementation of a better market positioning strategy, aimed at enhancing the typical characteristics of Toma due to the strong link with the territory, may assist farmers and cheese-makers in setting forward actions to improve their typical productions [52]. The enhancement of such a production chain can, therefore, be useful in the construction of an economic development model of the valleys and for the rehabilitation of the landscape.

As to the sustainability of the product, Toma di Lanzo's productive impacts on the environment, on the territory's ecosystem, on society, and on human well-being are well recognized. In fact, the interviewees positively assessed all these aspects (Figure 2). 
From our results, it emerged that the interviewees had a purely positive vision of the impact of mountain livestock farming related to the supply of ESs. The most positively perceived service is the one related to the "maintenance of landscape", followed by the aspects of "cultural identity" and "maintenance of local breeds". In a similar study within another alpine area, Reference [13] also identified the maintenance of a traditional and natural landscape as one of the services that achieved the highest scores. Interestingly, in a Swedish region [53], where neither cheese consumers nor cheese producers have strict relationships with the local territory or with its history, a high value was attributed to cultural heritage/food traditions and to the place and its history, as well as to the natural landscape and the presence of grazing animals, showing that these values are important even in different contexts.

Overall, our results are in line with those of other studies, showing a tendency of respondents to have a positive perception of the impact of mountain livestock farms on ESs [47,54-57]. In our study, the service that obtained the lowest degree of perception was the one related to leather and wool production. This result may be explained by the fact that, since the 1960s, the production of wool has started to decline due to the increasing importance and production of synthetic fibers [58].

According to our results, the perceptions of the impacts of Toma di Lanzo production and of ESs provided by mountain farming were affected by socio-demographic factors like sex, education level, and residence.

In accordance with the study by [30], women evaluated the impact of breeding more positively than men, particularly for the following ESs: "maintenance of local breeds", "improvement of water quality", "pollination", and "cultural identity".

The impact of the production of Toma di Lanzo is perceived as more positive by respondents with a medium or high education level than by respondents with a lower education level, with significant differences for the impact on the society of the Lanzo Valleys, confirming that the search for information and personal knowledge can have a strong influence on consumer attitudes and perception [59]. The educational level of the interviewees also significantly affected the perception of the impact of livestock breeding on two ESs: "pollination" and "habitat maintenance". Individuals with the lowest education level had a more negative perception than the other categories. This suggests that a higher level of education could be associated with a greater perception of ESs, particularly environmental ones [30]. However, a higher level of education does not always indicate a more "conscious" perception. In fact, experiential or local knowledge (non-formal) can also play a fundamental role in understanding ESs, particularly for those services related to multifunctional landscapes (i.e., soil formation, water regulation, forest products, recreational hunting, and food from cattle; [30]).

The residence of the interviewees also influenced the perception of both the impact of Toma production on the society of the Valleys and of ESs provided by mountain farming, especially those related to forest fire prevention. Interestingly, in our survey, non-residents showed a greater interest in Toma di Lanzo and a greater perception of ESs, perhaps because their use of the territory is derived from a conscious and targeted choice and is not taken for granted, as it might be for the residents. These considerations enhance the importance of integrating agricultural and tourism supply chains for fostering sustainable development in inner areas. A different perception of ESs by residents and non-residents could be justified by the fact that different stakeholders can have different relationships with the same ecosystem [60]. Differences in perceptions of the place of residence have also been noted by other authors $[30,61]$. For example, Reference [30] highlighted that there are conflicting differences in the perception of some ESs between inhabitants of rural and urban areas; people born and raised in rural contexts, where agriculture and livestock play a central role, have a different perception from that of those residing in urban areas, whose point of view is based more on the touristic aspect $[30,61]$. In order to value these touristic features, especially for non-residents, the coexistence of mountain farming with agritourist activities-i.e., accommodation, restoration, or other recreational activities-in the Lanzo Valleys is necessary, as already highlighted by [23]. Tourism in inner areas, especially in 
the mountains, is a complex phenomenon due to the different tourists' needs and the specific local features that vary considerably from one destination to another. Because of its nature, it does not allow the identification and implementation of standard strategies that are adoptable everywhere [62]. Furthermore, farmhouses tend to adopt more sustainable techniques that have positive impacts on biodiversity and natural resources [63].

As to the lack of differences recorded for the perception of ESs depending on age class and cultural background, this is possibly due to the unbalanced distribution of the sample in the categories of these classes, which, in some cases, presented a low sample size.

The positive view of mountain farming and its products coming out from our survey is confirmed by the low perception of the inefficiencies or of the potentially negative impacts that this activity can have on a territory. In fact, for the interviewees, livestock farming does not have a negative impact on the Lanzo Valleys, in line with the results of other authors [13]. According to our interviewees, the worst impact of livestock farming is represented by greenhouse gas (GHG) emissions, but it is still perceived as low. Although several studies show that the emission of greenhouse gases in extensive farms is greater than in intensive ones [64], if the Lyfe Cycle Assessment method for the evaluation of the environmental sustainability of mountain farms and their products is applied taking into account their ability to supply ESs, mountain production systems are shown to be more sustainable than intensive ones [14,52].

According to the interviewees, the future constraints that could affect mountain animal husbandry and compromise its benefits to the territory and society of the Lanzo Valleys are mainly the absence of policies/regulations to support livestock in mountain areas and the insufficient income generated by mountain livestock. These aspects indicate problems related to the limited economic sustainability of farms in marginal areas, such as the Lanzo Valleys, also because the market and public policies have so far not been able to adequately remunerate any non-provisioning services that they can provide [31]. A possible solution to the issue of economic sustainability may be represented by the integration of livestock production with a more sustainable form of tourism and valorization of local products to achieve profitable synergies, thus avoiding trade-offs [65]. The innovation goes towards making breeding complementary with tourist services (i.e., farmhouses), ranging from accommodation and restoration to recreation. The organization of festivals and local events focusing on the local cheese might also be useful to attract visitors, and they are, therefore, relevant for the tourism sector, but also for the local economy in general due to the consumption of local gastronomic products, as observed, for example, in a Spanish region [66].

\section{Conclusions}

Our results show that the interviewees appreciate the territory of the Lanzo Valleys and its typical products. In particular, most of the interviewees had a positive perception of the territory in relation to the landscape and the quality of life, and they showed a high interest in the local product, Toma di Lanzo. This confirms that mountain products promote the traceability of the output, the preservation of the territory, the environmental quality, the biodiversity, the cultural heritage, and the landscape traits [16], as well as, as a matter of fact, the ESs of the production site and their evolution in the history of mountain agriculture [67]. This highlights the high potential of Toma di Lanzo as a key element not only for the development of the territory, but also specifically for the promotion of tourism.

In conclusion, the coexistence of touristic activities and pasture-based livestock farming systems, possibly associated with a better promotion of mountain products like Toma di Lanzo, is desirable to maximize the sustainability of mountain regions [68]. Therefore, exhibitions and events to present Toma di Lanzo and its production process should be encouraged in order to spread knowledge about them, also in light of our results, which show the importance of education for the perception of ESs and consideration of the local product. The adoption of labels and brands, as well as the inclusion of more detailed information in the product label, could also be useful to communicate this 
extra value of Toma di Lanzo to the consumers. This is important especially for non-resident people, who demonstrated a high appreciation of the territory and of its product, and are potentially crucial for touristic development.

These strategies may help to highlight ESs and product characteristics and, therefore, to increase the income generated by mountain livestock farming, which is seen as one of the major constraints to the future development of these activities. However, other important perceived limitations are the absence of policies/regulations to support livestock in mountain areas and the lack of interest and participation by public bodies in the promotion and enhancement of the territory. To address this issue, farmers' associations should work to promote awareness among public bodies about these important topics, whose relevance for humankind should be acknowledged. Furthermore, a social analysis may allow the identification of the determinants that contribute the most to the development of agritourist activities and that could be used by policymakers as instruments for sustainable rurality [22].

For future research, it would certainly be advisable to enlarge the sample and to also take into account more diversified dimensions of the respondents (original agricultural, non-agricultural, new farmers, new inhabitants) because these factors can significantly affect the perception of ESs and of the local production [54]. A larger data set would also allow the performance of deeper statistical analyses and, perhaps, for multidimensional differences among the considered factors to be better highlighted, thus permitting a more complete understanding of the complex relationships between mountain farming, the typical cheese derived from this activity, and their perception by the local community in the light of potential tourism development.

Author Contributions: Conceptualization, L.B.; methodology, L.B. and M.Z.; data collection, R.M.; formal analysis, S.M. and R.M.; data curation, R.M.; writing—original draft preparation, all authors; writing-review and editing, L.B., D.G., and S.M.; supervision, L.B. All authors have read and agreed to the published version of the manuscript.

Funding: This research received no external funding.

Acknowledgments: We are extremely grateful to Laura Chianale, Chair of the Association of Toma di Lanzo Producers, for introducing us to the Lanzo Valleys and for her help in spreading the questionnaire. The contribution of Manuel Giacometto was also important for spreading the news about our survey through the local journal "La Voce di Ciriè e dintorni". Finally, we would also like to thank Enrichetta Valfrè for the English revision and all the respondents who dedicated their time to fill out our long questionnaire.

Conflicts of Interest: The authors declare no conflict of interest.

\section{References}

1. Hoffmann, I.; From, T.; Boerma, D. Ecosystem services provided by livestock species and breeds, with special consideration to the contributions of small-scale livestock keepers and pastoralists. FAO Commun. Genet. Resour. FOOD Agric. 2014, 66, 1-158.

2. Millennium Ecosystem Assessment. Ecosystems and Human Wellbeing: Synthesis; Island Press: Washington, DC, USA, 2005; ISBN 9781610914840.

3. Bernués, A.; Rodríguez-Ortega, T.; Ripoll-Bosch, R.; Alfnes, F. Socio-cultural and economic valuation of ecosystem services provided by Mediterranean mountain agroecosystems. PLoS ONE 2014, 9, e102479. [CrossRef]

4. FAO. The Contributions of Livestock Species and Breeds to Ecosystem Services; FAO: Roma, Italy, 2016.

5. Millennium Ecosystem Assessment. Available online: www.millenniumassessment.org/en/index.html (accessed on 3 September 2020).

6. FAO. Livestock's Long Shadow; FAO: Roma, Italy, 2006.

7. Bätzing, W. Uno sguardo da lontano. In Libellule in Volo. Trentenni All'opera Oggi Nelle Valli di Lanzo; Coletti, M., Guglielmotto-Ravet, B., Eds.; Società storica delle Valli di Lanzo: Lanzo Torinese, Italy, 2015; pp. 6-10.

8. MacDonald, D.; Crabtree, J.R.; Wiesinger, G.; Dax, T.; Stamou, N.; Fleury, P.; Gutierrez Lazpita, J.; Gibon, A. Agricultural abandonment in mountain areas of Europe: Environmental consequences and policy response. J. Environ. Manag. 2000, 59, 47-69. [CrossRef]

9. Viazzo, P.P. Comunità Alpine: Ambiente, Popolazione, Struttura Sociale Nelle Alpi Dal Xvi Secolo Ad Oggi; Il Mulino: Bologna, Italy, 1990. 
10. Revelli, N. Il Mondo Dei Vinti; Einaudi: Torino, Italy, 1977.

11. Salsa, A. Il Tramonto Delle Identità Tradizionali: Spaesamento e Disagio Esistenziale Nelle ALPI; Priuli \& Verlucca: Scarmagno, Italy, 2007.

12. Streifeneder, T.; Ruffini, F.V.; Eiselt, B. Change of agricultural structure and land use in the Alps between 1980 and 2000. In Proceedings of the Multifunctionality of Landscapes-Analysis, Evaluation and Decision Support; J.-Liebig University: Gießen, Germany, 2005; p. 175.

13. Faccioni, G.; Sturaro, E.; Ramanzin, M.; Bernués, A. Socio-economic valuation of abandonment and intensification of Alpine agroecosystems and associated ecosystem services. Land Use Policy 2019, 81, 453-462. [CrossRef]

14. Battaglini, L.; Bovolenta, S.; Gusmeroli, F.; Salvador, S.; Sturaro, E. Environmental sustainability of Alpine livestock farms. Ital. J. Anim. Sci. 2014, 13, 431-443. [CrossRef]

15. Ellis, A.; Park, E.; Kim, S.; Yeoman, I. What is food tourism? Tour. Manag. 2018, 68, 250-263. [CrossRef]

16. McMorran, R.; Santini, F.; Guri, F.; Gomez-y-Paloma, S.; Price, M.; Beucherie, O.; Monticelli, C.; Rouby, A.; Vitrolles, D.; Cloye, G. A mountain food label for Europe? Rev. Géogr. Alp. 2015. [CrossRef]

17. Marcoz, E.M.; Melewar, T.C.; Dennis, C. The Value of Region of Origin, Producer and Protected Designation of Origin Label for Visitors and Locals: The Case of Fontina Cheese in Italy. Int. J. Tour. Res. 2016, 18, $236-250$. [CrossRef]

18. Humer-Gruber, A. Where farmers see their role-Influence on sustainable regional development approaches in Alpine biosphere reserves. J. Prot. Mt. Areas Res. Manag. 2018, 10, 28-35. [CrossRef]

19. Bonadonna, A. What Does the Optional Quality Term "Mountain Product" Involve? The Biellese Mountain (North-West Italy) Farmers' Opinions. Mediterr. J. Soc. Sci. 2016, 7, 18-23. [CrossRef]

20. Luthe, T.; Wyss, R.; Schuckert, M. Network governance and regional resilience to climate change: Empirical evidence from mountain tourism communities in the Swiss Gotthard region. Reg. Environ. Chang. 2012, 12, 839-854. [CrossRef]

21. Fassio, G.; Battaglini, L.M.; Porcellana, V.; Viazzo, P.P. The role of the family in mountain pastoralism-change and continuity. Mt. Res. Dev. 2014, 34, 336-343. [CrossRef]

22. Lupi, C.; Giaccio, V.; Mastronardi, L.; Giannelli, A.; Scardera, A. Exploring the features of agritourism and its contribution to rural development in Italy. Land Use Policy 2017, 64, 383-390. [CrossRef]

23. Genovese, D.; Culasso, F.; Giacosa, E.; Battaglini, L.M. Can livestock farming and tourism coexist in mountain regions? A new business model for sustainability. Sustainability 2017, 9, 2021. [CrossRef]

24. Bentivoglio, D.; Bucci, G.; Finco, A. Farmers' general image and attitudes to traditional mountain food labelled: A swot analysis. Calitatea 2019, 20, 48-55.

25. Martins, N.; Ferreira, I.C.F.R. Mountain food products: A broad spectrum of market potential to be exploited. Trends Food Sci. Technol. 2017, 67, 12-18. [CrossRef]

26. Boesch, M.; Renner, E.; Siegrist, D. "Brandscaping": From traditional cultural landscapes to "label regions": A strategic scheme to achieve sustainable regional development in the Swiss Alps. Mt. Res. Dev. 2008, 28, 100-104. [CrossRef]

27. Bovolenta, S.; Krištof, P.; Ressi, W.; Sturaro, E.; Trentin, G.; Venerus, S. I servizi ecosistemi ci e L ' indicazione "prodotto di montagna" a sostegno delle filiere lattiero- casearie di montagna: IL progetto Topvalue. Quad. SoZooAlp 2019, 10, 61-72.

28. Bonadonna, A.; Peira, G.; Giachino, C.; Molinaro, L. Traditional cheese production and an EU labeling scheme: The Alpine cheese producers' opinion. Agriculture 2017, 7, 65. [CrossRef]

29. Cooper, T.; Hart, K.; Baldock, D. Provision of Public Goods through Agriculture in the European Union; Institute for European Environmental Policy: London, UK, 2009.

30. Martín-López, B.; Iniesta-Arandia, I.; García-Llorente, M.; Palomo, I.; Casado-Arzuaga, I.; Del Amo, D.G.; Gómez-Baggethun, E.; Oteros-Rozas, E.; Palacios-Agundez, I.; Willaarts, B.; et al. Uncovering ecosystem service bundles through social preferences. PLoS ONE 2012, 7, e38970. [CrossRef]

31. Ramanzin, M.; Battaglini, L.; Bovolenta, S.; Gandini, G.; Mattiello, S.; Sarti, F.M.; Sturaro, E. Sistemi Agro-Zootecnici e Servizi Ecosistemici. Quad. SoZooAlp 2019, 10, 11-36.

32. Schirpke, U.; Timmermann, F.; Tappeiner, U.; Tasser, E. Cultural ecosystem services of mountain regions: Modelling the aesthetic value. Ecol. Indic. 2016, 69, 78-90. [CrossRef] [PubMed] 
33. Zoderer, B.M.; Tasser, E.; Erb, K.H.; Lupo Stanghellini, P.S.; Tappeiner, U. Identifying and mapping the tourists' perception of cultural ecosystem services: A case study from an Alpine region. Land Use Policy 2016, 56, 251-261. [CrossRef]

34. Schirpke, U.; Altzinger, A.; Leitinger, G.; Tasser, E. Change from agricultural to touristic use: Effects on the aesthetic value of landscapes over the last 150 years. Landsc. Urban Plan. 2019, 187, 23-35. [CrossRef]

35. Haida, C.; Rüdisser, J.; Tappeiner, U. Ecosystem services in mountain regions: experts' perceptions and research intensity. Reg. Environ. Chang. 2015, 16, 1989-2004. [CrossRef]

36. Lopes, C.; Leitão, J.; Rengifo-Gallego, J. Place branding: Revealing the neglected role of agro food products. Int. Rev. Public Nonprofit Mark. 2018, 15, 497-530. [CrossRef]

37. Kavaratzis, M.; Hatch, M.J. The dynamics of place brands: An identity-based approach to place branding theory. Mark. Theory 2013, 13, 69-86. [CrossRef]

38. Santini, F.; Guri, F.; Gomez, S. Labelling of Agricultural and Food Products of Mountain Farming: Executive Summary; Publications Office of the European Union: Luxembourg, 2013; ISBN 978-92-79-28275-1.

39. Zuliani, A.; Esbjerg, L.; Grunert, K.G.; Bovolenta, S. Animal welfare and mountain products from traditional dairy farms: How do consumers perceive complexity? Animals 2018, 8, 207. [CrossRef]

40. Baritaux, V.; Tebby, C.; Revoredo-Giha, C. How well do food retailers know their customers? the case of mountain food products in Europe. J. Chain Netw. Sci. 2011, 11, 223-234. [CrossRef]

41. Leroy, G.; Hoffmann, I.; From, T.; Hiemstra, S.J.; Gandini, G. Perception of livestock ecosystem services in grazing areas. Animal 2018, 12, 2627-2638. [CrossRef]

42. Ermolaev, V.A.; Yashalova, N.N.; Ruban, D.A. Cheese as a tourism resource in Russia: The first report and relevance to sustainability. Sustainability 2019, 11, 5520. [CrossRef]

43. Lezzi, B. Relazione Annuale Sulla Strategia Nazionale per le Aree Interne. 2018. Available online: http://old2018.agenziacoesione.gov.it/opencms/export/sites/dps/it/documentazione/Aree_interne/ Presentazione/Relazione_CIPE_ARINT_311218.pdf (accessed on 3 September 2020).

44. Reteuna, D. La migrazione degli Accipitriformes, Falconiformes e Ciconiiformes attraverso le Valli di Lanzo. Riv. Piem. St. Nat. 1994, 15, 127-153.

45. Guglielmotto Ravet, B. Villeggiatura Ambita e Ambizione Turistica. Available online: http://www.dislivelli. eu/blog/villeggiatura-ambita-e-ambizione-turistica.html (accessed on 18 June 2020).

46. Anagrafe Nazionale Zootecnica-Statistiche Banca Dati Nazionale dell'Anagrafe Zootecnica. Available online: https://www.vetinfo.it/j6_statistiche/\#/ (accessed on 16 June 2020).

47. Oteros-Rozas, E.; Martín-López, B.; González, J.A.; Plieninger, T.; López, C.A.; Montes, C. Socio-cultural valuation of ecosystem services in a transhumance social-ecological network. Reg. Environ. Chang. 2014, 14, 1269-1289. [CrossRef]

48. Schmidt, K.; Walz, A.; Martín-López, B.; Sachse, R. Testing socio-cultural valuation methods of ecosystem services to explain land use preferences. Ecosyst. Serv. 2017, 26, 270-288. [CrossRef] [PubMed]

49. Scholte, S.S.K.; van Teeffelen, A.J.A.; Verburg, P.H. Integrating socio-cultural perspectives into ecosystem service valuation: A review of concepts and methods. Ecol. Econ. 2015, 114, 67-78. [CrossRef]

50. Zucaro, M.; Genovese, D.; Battaglini, L.M. Percezione dei Servizi Ecosistemici dell'Allevamento di Montagna. Un'Indagine in Val Di Susa (To). Quad. SoZooAlp 2019, 10, 37-47.

51. Giacometto, M. Una tesi universitaria milanese sulla Toma e sugli allevamenti. La Voce Ciriè Dintorni 2019, $13,42$.

52. Verduna, T.; Blanc, S.; Battaglini, L.M. Sostenibilità della Zootecnia Alpina da Latte in Piemonte: Il Caso di Studio del PAT Toma di Lanzo. Quad. SoZooAlp 2019, 10, 127-138.

53. Rytkönen, P.; Bonow, M.; Girard, C.; Tunón, H. Bringing the consumer back in-The motives, perceptions, and values behind consumers and rural tourists' decision to buy local and localized artisan food-A Swedish example. Agriculture 2018, 8, 58. [CrossRef]

54. Bernués, A.; Rodríguez-Ortega, T.; Ripoll Bosch, R.; Casasús, I. A qualitative research on Spanish farmers and citizens perceptions of ecosystem services provided by mountain livestock farming. In Proceedings of the 17th Meeting of the FAO-CIHEAM Mountain Pasture Network, Trivero, Italy, 5-7 June 2013; pp. 12-16.

55. Lamarque, P.; Tappeiner, U.; Turner, C.; Steinbacher, M.; Bardgett, R.D.; Szukics, U.; Schermer, M.; Lavorel, S. Stakeholder perceptions of grassland ecosystem services in relation to knowledge on soil fertility and biodiversity. Reg. Environ. Chang. 2011, 11, 791-804. [CrossRef] 
56. Oteros-Rozas, E.; González, J.A.; Martín-López, B.; López, C.A.; Zorrilla-Miras, P.; Montes, C. Evaluating ecosystem services in transhumance cultural landscapes. An interdisciplinary and participatory framework. Gaia 2012, 21, 185-193. [CrossRef]

57. Oteros-Rozas, E.; Martín-López, B.; López, C.A.; Palomo, I.; González, J.A. Envisioning the future of transhumant pastoralism through participatory scenario planning: A case study in Spain. Rangel. J. 2013, 35, 251-272. [CrossRef]

58. Simpson, W.S.; Crawshaw, G. Wool: Science and Technology; Woodhead Publishing: Cambridge, UK, 2002; ISBN 978-1855735743.

59. Zepeda, L.; Deal, D. Organic and local food consumer behaviour: Alphabet theory. Int. J. Consum. Stud. 2009, 33, 697-705. [CrossRef]

60. Bidegain, I.; Cerda, C.; Catalán, E.; Tironi, A.; López-Santiago, C. Social preferences for ecosystem services in a biodiversity hotspot in South America. PLoS ONE 2019, 14, e215715. [CrossRef] [PubMed]

61. López-Santiago, C.A.; Oteros-Rozas, E.; Martín-López, B.; Plieninger, T.; Martín, E.G.; González, J.A. Using visual stimuli to explore the social perceptions of ecosystem services in cultural landscapes: The case of transhumance in Mediterranean Spain. Ecol. Soc. 2014, 19. [CrossRef]

62. Duglio, S.; Bonadonna, A.; Letey, M.; Peira, G.; Zavattaro, L.; Lombardi, G. Tourism development in inner mountain areas-the local stakeholders' point of view through a mixed method approach. Sustainability 2019, 11, 5997. [CrossRef]

63. Mastronardi, L.; Giaccio, V.; Giannelli, A.; Scardera, A. Is agritourism eco-friendly? A comparison between agritourisms and other farms in italy using farm accountancy data network dataset. Springerplus 2015, 4, 1-12. [CrossRef]

64. Ogino, A.; Sommart, K.; Subepang, S.; Mitsumori, M.; Hayashi, K.; Yamashita, T.; Tanaka, Y. Environmental impacts of extensive and intensive beef production systems in Thailand evaluated by life cycle assessment. J. Clean. Prod. 2016, 112, 22-31. [CrossRef]

65. Bernués, A.; Olaizola, A.; Corcoran, K. Extrinsic attributes of red meat as indicators of quality in Europe: An application for market segmentation. Food Qual. Prefer. 2003, 14, 265-276. [CrossRef]

66. Folgado-Fernández, J.A.; Di-Clemente, E.; Hernández-Mogollón, J.M. Food festivals and the development of sustainable destinations. The case of the cheese fair in Trujillo (Spain). Sustainability 2019, 11, 2922. [CrossRef]

67. Locatelli, B.; Lavorel, S.; Sloan, S.; Tappeiner, U.; Geneletti, D. Characteristic trajectories of ecosystem services in mountains. Front. Ecol. Environ. 2017, 15, 150-159. [CrossRef]

68. Marín-Yaseli, M.L.; Martínez, T.L. Competing for Meadows. Mt. Res. Dev. 2003, 23, 169-176. [CrossRef] 